\title{
'Char-cola'-Using cola to increase the palatability of activated charcoal: A review of the literature
}

\section{By Christopher Picard, CD, BSN, RN, ENC(C), and Gel Cortiguierra, BScN, RN}

$\mathrm{A}$ ctivated charcoal (AC) is a porous carbon product formed by superheating carbon compounds. The process results in small particles with an exceptionally large surface area. The large surface area is clinically useful for its ability to bind with drugs, chemicals, and organic compounds. This binding or "adsorption" is useful in the clinical context because when ingested it binds with toxins and prevents gastric absorption, leaving the AC-bound chemicals to be excreted in feces (AACT/ EAPCCT, 2005). Activated charcoal has been recognized as a gastric decontaminant since the early 1800s (Juurlink, 2015), and is still the most commonly used agent for GI decontamination in acute poisoning (Watson 2005). It's used for a wide variety of poisonings and is generally quite safe; but getting patients, especially pediatric patients, to consume the medication orally can be difficult. This article will review the use of AC in poisoning: which ingestions it is useful for, the evidence to support its use, typical dosing of AC, and we offer evidence-based suggestions on how flavouring agents can increase palatability and patient adherence.

AC will bind with most drugs. It is effective for most poisonings. However, the adsorption process relies on weak binding and factors such as toxin volume, temperature, solubility/ionization of the toxin, $\mathrm{pH}$, and the presence of other gastric contents. For this reason it's easier to describe when $\mathrm{AC}$ is ineffective, or requires multiple doses, than it is to create an exhaustive list of drugs it will bind to. Strong ions, heavy metals and alcohols are generally not well adsorbed to AC (Olson, 2010; AACT/EAPCCT, 2005). Substances not well adsorbed by AC can be recalled by the "PHAILS" mnemonic: Pesticides, Hydrocarbons, Acids and Alkalis, Iron, Lithium, and Solvents (Davis \& Anderson, 2017). Although single dose AC is the norm, occasionally multiple doses of AC may be given to select patients (Eddleston et al., 2008). Drugs that may require multiple dose AC (MDAC) administration can be recalled by the mnemonic "ABCD": Antimalarials (quinine) and aminophylline (theophylline), Barbiturates (phenobarbital) and Beta-blockers (nadolol), Carbamazepine, and Dapsone (Stephen et al., 2001).

The evidence to support AC use is of relatively low quality. Conducting randomized controlled trials (RCT) on poisoned patients is ethically and logistically challenging. As a result, the use of AC is not well supported with RCT evidence. In-vitro studies show that AC will strongly bind to common toxins (Juurlink, 2016). AC has also been shown to decreases serum levels with sub-toxic drug ingestions in volunteer studies when compared to control (Olson, 2010; Juurlink, 2016). These studies have shown $\mathrm{AC}$ to be effective in reducing rates of drug absorption by $30-63 \%$ depending on the drug and time of $\mathrm{AC}$ administration (Olson, 2010). A meta-analysis of volunteer studies found that $\mathrm{AC}$ reduced drug absorption by an average of $38 \%$ if administered within one hour, and that it continued to be effective at four hours with a median reduction of $27.4 \%$ (Jürgens, Hoegberg, \& Graudal, 2009). Although AC has shown to be effective at reducing absorption rates and decreasing serum drug levels, the two randomized controlled trials that have assessed AC have not shown a mortality benefit (Cooper, Le Couteur, Richardson, \& Buckley, 2005; Eddleston et al., 2008). The RCTs should be interpreted with caution. In one, half the patients were poisoned with pesticides (and are likely not generalizable to pharmaceutical overdoses) (Eddelston et a., 2008), and in the other the patients were toxic with either acetaminophen, which has a direct antidote, or, benzodiazepines, which tend not to be actively treated (Cooper et al., 2005). Both studies had large numbers of patients with delays greater than four hours to AC administration.

The outcomes of case reports are generally positive and show several clinically significant, non-mortality, benefits of $\mathrm{AC}$ including: reduction in serum drug levels (AACT/EAPCCT, 2005); reductions in toxin-specific complications such as QTc intervals (Friberg, Isbister, \& Duffull, 2006), hepatotoxicity (Chiew et al., 2017), rates of delirium (Page, Duffull, Whyte, \& Isbister, 2008), and antidote dose requirement (Chiew et al., 2017). While the efficacy is a topic for debate, the general safety of $\mathrm{AC}$ is not, with complications tending to be outweighed by the potential benefits of judicious AC administration (Juurlink, 2016).

Although there is some disagreement on the efficacy of AC, it is generally agreed upon that the sooner AC can be administered after poisoning, the better the adsorption will be (AACT/ EAPCCT, 2005). Usual doses of activated charcoal are $0.5-1 \mathrm{~g} / \mathrm{kg}$ for pediatric patients and typical initial adult doses of 50-100g with additional $50 \mathrm{~g}$ doses potentially given every four hours (AACT/EAPCCT, 2005; Chiew et al., 2015). The evidence suggests that $\mathrm{AC}$ should not be given by nasogastric tube or used in patients who cannot maintain their own airway, because of the risk for AC aspiration and resultant pneumonitis (AACT/ EAPCCT, 2005). The risks and benefits of AC should also be weighed for patients with, or at risk for GI perforation, as it may obscure endoscopic investigation of the stomach (AACT/ EAPCCT, 2005). Ultimately, regional practice may be guided by specific institutional policies, and individual dosing may vary between patients and toxins. Clinical judgment is required.

Most patients will tolerate AC orally, but palatability, especially in pediatric patients, can present a significant barrier to timely 
ingestion. A number of studies have examined the addition of flavouring agents to address this issue. The majority of these studies have investigated the palatability of mixing AC with flavouring agents such as yogurt, juice, milk or cola (Dagnone, Matsui, \& Rieder, 2002; Skokan, Junkins, Corneli, \& Schunk, 2001; Cheng \& Ratnapalan, 2007; Groth Hoegberg, Christophersen, Christensen, \& Angelo, 2005). Of the four studies identified, only one examined palatability for adults, and compared AC and yogurt versus $\mathrm{AC}$ and water, and found there to be no difference in palatability between the two mixtures (Groth Hoegberg et al., 2005). Pediatric studies, conversely, have consistently found cola to be the preferred mix for AC in terms of flavour, ease of swallowing, and overall preference (Dagnone et al., 2002; Skokan et al., 2001; Cheng \& Ratnapalan, 2007).

There are concerns that the addition of flavouring agents could change the adsorptive capacity of AC (Scharman \& Krenzelok, 1994). Research into this question has proven these concerns unfounded. In-vitro studies have evaluated the effects of adding ice cream, yogurt, or food mixtures on the adsorptive capacity of $\mathrm{AC}$ and the effect on clearing toxins, and have concluded that although food can impair AC adsorption of toxins by approximately 11-26\% (Groth Hoegberg et al., 2005), the AC was still able to provide effective decontamination and clinical effect (Groth Hoegberg et al., 2005). Furthermore, when AC is mixed at concentrations greater than 5:1 the impairment of adsorption approached insignificance (AC 92\% adsorption, AC and food $90 \%$ ), suggesting that in a clinical setting the use of a flavouring agent or the contents of the stomach will have little effect on the action of AC. Moreover, when cola-AC was compared to cola-water mixtures in volunteer studies the cola-AC combination was not statistically different in its capacity to prevent acetaminophen absorption (Rangan et al., 2001).

$\mathrm{AC}$ is a generally safe drug, it's cheap, and can effectively bind with a great many toxins. But administering it in a timely way can be a challenge. Improving AC palatability by using cola as a flavouring agent improves patient satisfaction, and may increase patient compliance. Improving its flavour with additives is within an emergency nurse's scope of practice, is well supported by research, and should be considered whenever administering the medication. Anecdotally, we have seen dramatic improvements in AC compliance in both the pediatric and adult populations when AC is mixed with cola. For children there is an improvement in flavour, the fizz is fun, and the colour of the cola doesn't change with the addition of AC. For adults there is less of a chance that allergies or aversions to dairy will present a barrier to using it as an additive. From a nursing perspective, cola is a clear winner as it's shelf stable, and readily available wherever there is a vending machine.

\section{About the authors}

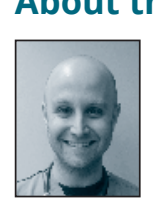
Christopher Picard, CD, BSN, RN, ENC(C), has worked in tertiary, rural, and remote areas, as an emergency nurse, and in pre-hospital, clinical and austere roles domestically and abroad, as a medic with the Canadian Forces. He currently works as an emergency nurse at the Royal Alexandra Hospital in Edmonton, $A B$. His research interests are trauma care, evidence-based practice and knowledge translation.

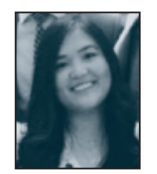

Gel Cortiguierra, $B S c N, R N$, is a recent graduate from the University of Alberta. As an undergraduate nurse, she has worked in several acute settings including general adult medicine/surgery, and pediatric surgery. While completing her nursing degree, she has volunteered for several humanitarian organizations, which sparked her interests in emergency and global health nursing. She hopes to use her nursing skills and knowledge to work with organizations working with developing countries affected by endemic diseases and refugees. She currently works as an emergency nurse at the Royal Alexandra Hospital in Edmonton, AB. In her free time, she enjoys travelling, reading and drawing/painting.

\section{REFERENCES}

American Academy of Clinical Toxicology, \& European Association of Poisons Centres and Clinical Toxicologists. (2005). Position paper: Single-dose activated charcoal. Clinical Toxicology, 43(2), 61-87.

Cheng, A., \& Ratnapalan, S. (2007). Improving the palatability of activated charcoal in pediatric patients. Pediatric emergency care, 23(6), 384-386.

Chiew, A.L., Fountain, J.S., Graudins, A., Isbister, G.K., Reith, D., \& Buckley, N.A. (2015). Summary statement: New guidelines for the management of paracetamol poisoning in Australia and New Zealand. Med J Aust, 203(5), 215-218.

Chiew, A.L., Isbister, G.K., Kirby, K.A., Page, C.B., Chan, B.S., \& Buckley, N.A. (2017). Massive paracetamol overdose: An observational study of the effect of activated charcoal and increased acetylcysteine dose (ATOM-2). Clinical Toxicology, 55(10), 1055-1065.

Cooper, G.M., Le Couteur, D.G., Richardson, D., \& Buckley, N.A. (2005). A randomized clinical trial of activated charcoal for the routine management of oral drug overdose. Qjm, 98(9), 655-660.

Dagnone, D., Matsui, D., \& Rieder, M.J. (2002). Assessment of the palatability of vehicles for activated charcoal in pediatric volunteers. Pediatric emergency care, 18(1), 19-21.
Davis, S.P., \& Anderson, D.D. (2017). Activated charcoal: A consideration for use in primary care practice of advanced practice nurses. Journal of Cultural Diversity, 24(3).

Eddleston, M., Juszczak, E., Buckley, N.A., Senarathna, L., Mohamed, F., Dissanayake, W., Hittarage, A., ... Ox-Col Poisoning Study collaborators. (2008). Multiple-dose activated charcoal in acute self-poisoning: A randomised controlled trial. Lancet, 371, 579-87.

Friberg, L.E., Isbister, G.K., \& Duffull, S.B. (2006). Pharmacokineticpharmacodynamic modelling of $\mathrm{QT}$ interval prolongation following citalopram overdoses. British Journal of Clinical Pharmacology, 61(2), 177-190.

Groth Hoegberg, L.C., Christophersen, A.B., Christensen, H.R., \& Angelo, H.R. (2005). Comparison of the adsorption capacities of an activated-charcoal-yogurt mixture versus activated-charcoalwater slurry in vivo and in vitro. Clinical Toxicology, 43(4), 269-275.

Jürgens, G., Hoegberg, L.G., \& Graudal, N.A. (2009). The effect of activated charcoal on drug exposure in healthy volunteers: A meta-analysis. Clinical Pharmacology \& Therapeutics, 85(5), 501-505. 
Juurlink, D.N. (2016). Activated charcoal for acute overdose: a reappraisal. British Journal of Clinical Pharmacology, 81(3), 482-487.

Olson, K.R. (2010). Activated charcoal for acute poisoning: One toxicologist's journey. Journal of Medical Toxicology, 6(2), 190-198.

Page, C.B., Duffull, S.B., Whyte, I.M., \& Isbister, G.K. (2008). Promethazine overdose: Clinical effects, predicting delirium and the effect of charcoal. QJM: An International Journal of Medicine, 102(2), 123-131.

Rangan, C., Nordt, S. P., Hamilton, R., Ingels, M., \& Clark, R. F. (2001). Treatment of acetaminophen ingestion with a superactivated charcoal-cola mixture. Annals of emergency medicine, 37(1), 55-58.
Scharman, E.J., \& Krenzelok, E.P. (1994). Nursing attitudes towards charcoal administration-Impact on patient care. Veterinary and human toxicology, 36(5), 472-474.

Skokan, E.G., Junkins, E.P., Corneli, H.M., \& Schunk, J.E. (2001). Taste test: Children rate flavoring agents used with activated charcoal. Archives of Pediatrics \& Adolescent Medicine, 155(6), 683-686.

Stephen, A.C., Jagoda, A., Brillman, J., Bukata, R., Fesmire, F.M., \& Gai, F. (2001). Toxicology update: A rational approach to managing the poisoned patient. Emerg Med Prac.

Watson, W.A., Litovitz, T.L., Rodgers, G.C., Klein-Schwartz, W., Reid, N., Youniss, J., ... \& Wruk, K.M. (2005). 2004 annual report of the American Association of Poison Control Centers toxic exposure surveillance system. The American Journal of Emergency Medicine, 23(5), 589-666.

\section{(3) Medic Alert FOUNDATION CANADA}

\section{WORKING TOGETHER. SAVING LIVES DAILY.}

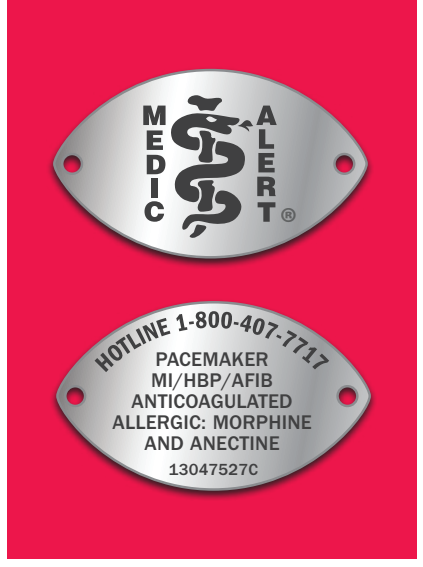

LOOK

for "MedicAlert" on

the ID to confirm it's the authentic MedicAlert ID.

READ the vital information on the back.

\section{CAL the 24/7 emergency} hotline answered in an average of $\mathbf{5}$ seconds providing detailed patient information.

\section{medicalert.ca/healthcare-providers}

